Provided for non-commercial research and education use. Not for reproduction, distribution or commercial use.

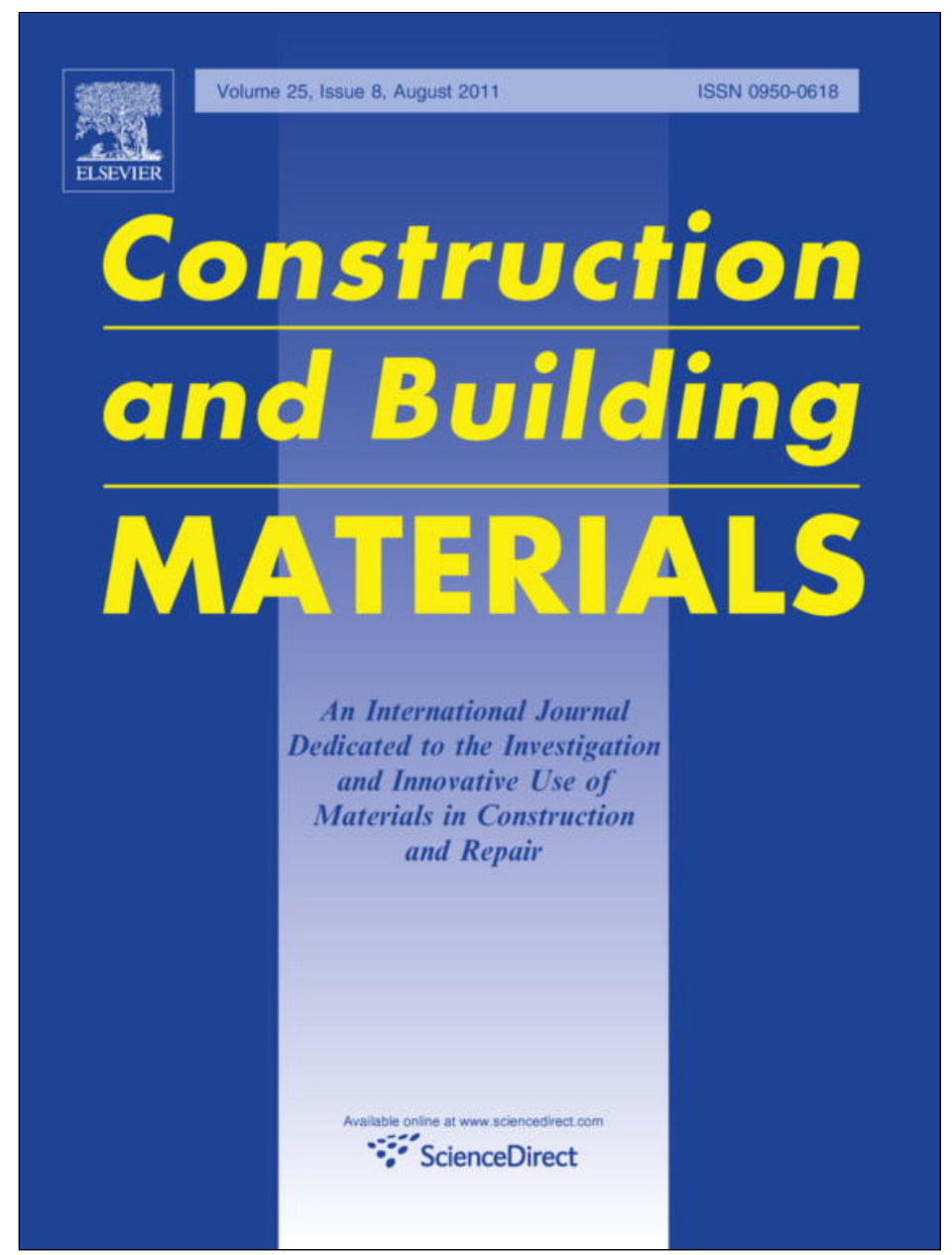

This article appeared in a journal published by Elsevier. The attached copy is furnished to the author for internal non-commercial research and education use, including for instruction at the authors institution and sharing with colleagues.

Other uses, including reproduction and distribution, or selling or licensing copies, or posting to personal, institutional or third party websites are prohibited.

In most cases authors are permitted to post their version of the article (e.g. in Word or Tex form) to their personal website or institutional repository. Authors requiring further information regarding Elsevier's archiving and manuscript policies are encouraged to visit:

http://www.elsevier.com/copyright 


\title{
Concrete retrofitting using metakaolin geopolymer mortars and CFRP
}

\author{
E. Vasconcelos ${ }^{\text {a }}$, S. Fernandes ${ }^{\text {a }}$, J.L. Barroso de Aguiar ${ }^{\mathrm{a}}$, F. Pacheco-Torgal ${ }^{\mathrm{b}, *}$ \\ ${ }^{a}$ University of Minho, Department of Civil Engineering, 4800 Guimarães, Portugal \\ ${ }^{\mathrm{b}}$ University of Minho, C-TAC Research Unit, 4800 Guimarães, Portugal
}

\section{A R T I C L E I N F O}

\section{Article history:}

Received 7 November 2010

Received in revised form 5 February 2011

Accepted 1 March 2011

Available online 27 March 2011

\section{Keywords:}

Gepolymeric mortars

Concrete retrofitting

CFRP

Adhesion strength

\begin{abstract}
A B S T R A C T
This paper presents results about the use of metakaolin based geopolymers mortars for retrofitting purposes. Two main situations are addressed, the use of geopolymeric mortars as a repairing layer or as a binding agent to insure the adhesion between CFRP sheets and the concrete substrate. Several compositions of metakaolin geopolymer mortars were executed by varying the percentage of sand/binder mass ratio and the concentration of sodium hydroxide. It was found that metakaolin geopolymer mortars show a high mechanical resistance and a relevant adhesion to the concrete substrate. Although their adhesion strength is lower than the one present by commercial pre-pack repair mortars, they are very cost-effective (5-10 times less expensive). On the other hand, the adhesion strength between CFRP and geopolymer mortars proved to be lower than expected which could be due to the fact that the composition of the geopolymeric mortars was not optimized and also to the fact that the CFRP used was not prone to this kind of application.
\end{abstract}

(c) 2011 Elsevier Ltd. All rights reserved.

\section{Introduction}

Geopolymeric binders appear to be an alternative to ordinary Portland cement (OPC), due to high mechanical performances and environmental advantages. According to some authors [1] durability is the most important issue on determining the success of these new materials (Fig. 1). Geopolymeric binders generates $80 \%$ less carbon dioxide than Portland cement [1]. Weil et al. [2] mentioned that in comparison to OPC concrete the global warming potential (GWP) of geopolymeric concrete is 70\% lower. The cost of geopolymeric based concrete is one of the major factors which still remains a severe disadvantage over Portland cement based concrete explaining why this new product is not yet a current alternative [3-5]. Currently geopolymeric based concrete only becomes economically competitive for high performance structural purposes. However, future increase cost of OPC due to European Emissions Trading Scheme (ETS) that will put a price on carbon dioxide emissions generated during clinker production will reduce the economic advantage of this material. In the short term the above cited disadvantage means that the study of geopolymeric applications should focus on high cost materials such as, commercial concrete repair mortars. Pacheco-Torgal et al. [6-8] show that geopolymeric mortars based on tungsten mine wastes can be as much as 7 times cheaper than current commercial repair mortars. But if the cost to bond strength ratio were compared the differences are even higher, with the cost of the cheapest commercial repair mortar being 13.8 times higher than the geopolymeric mortars. A new develop-

\footnotetext{
* Corresponding author.

E-mail address: torgal@civil.uminho.pt (F. Pacheco-Torgal).
}

ment in the repair and strengthening of reinforced concrete systems is the use of carbon fibre reinforced polymers (CFRP) strips bonded to concrete substrate with epoxy resins. This method is a relatively new retrofitting method, developed first in Japan $[9,10]$. Epoxy adhesive being used in the construction industry is very sensitive to temperature variations. Both experimental and finite element results show that the epoxy temperature should not exceed $70{ }^{\circ} \mathrm{C}$ in order to maintain the integrity between the CFRP and concrete [11]. It is noted that frequently exposure to direct sunlight causes temperatures higher than $70^{\circ} \mathrm{C}$ which causes malfunction CFRP. This means that adhesive materials that remain stable with higher temperatures are needed. Since geopolymers are known to possess high stability at high temperature, these materials can be an alternative to epoxy resins. This papers presents results about the concrete retrofitting using of metakaolin based geopolymers mortars.

\section{Experimental work}

2.1. Materials

2.1.1. Geopolymer mortars

Fig. 2 shows the gradation and the physical characteristics of the fine aggregate. It has a specific gravity of 2.6 and a $24 \mathrm{~h}$ water absorption of $1.2 \%$. The metakaolin used in this study was subject to a thermal treatment at $650^{\circ} \mathrm{C}$ during a few seconds using a flash calcination apparatus. Its chemical composition is shown in Table 1 . Geopolymeric mortars were a mixture of aggregates, metakaolin, calcium hydroxide and alkaline silicate solution. The factors analysed were, aggregate/binder mass ratio (30\%, 60\%; 90\%), sodium hydroxide concentration $(12 \mathrm{M}, 14 \mathrm{M}$, $16 \mathrm{M}$ ) and the percentage substitution of metakaolin by calcium hydroxide in the mixture $(5 \%, 10 \%)$. The use minor calcium hydroxide percentages improve the compressive strength of geopolymeric mortars [6]. The explanation for that is related to the formation of two different phases, geopolimeric gel and calcium silicate 




Fig. 1. Diagram showing some of the interrelationships between technical and scientific aspects of geopolymer binder technology [1].

hydrates, being that the former acts as microaggregates [12]. Experimental trials showed that a higher sand content leads to a very stiff behaviour of the geopolymeric mortars. The alkaline activator was prepared prior to use. An activator with sodium hydroxide and sodium silicate solution $\left(\mathrm{Na}_{2} \mathrm{O}=13.5 \%, \mathrm{SiO}_{2}=58.7 \%\right.$, and water $=45.2 \%$ ) was used with a mass ratio of $1: 2.5$. Previous investigations showed that this ratio lead to the highest compressive strength results in alkali-activated mortars [6]. The sand, metakaolin and calcium hydroxide were dry mixed before added to the activator. Distiled water was used to dissolve the sodium hydroxide flakes to avoid the effect of unknown contaminants in the mixing water. The alkaline activator was prepared prior to use. No extra water has been added.

\subsubsection{OPC concrete substrate}

The concrete mix used for substrate beams and slabs is described in Table 2 . Concrete slabs were cast into moulds with $300 \times 200 \times 50 \mathrm{~mm}$. As for beams they have $850 \times 100 \times 80 \mathrm{~mm}$. The concrete specimens were cured immersed in water during 28 days. This curing period provides an almost complete concrete hydration as old concretes in field practice. Workability of the fresh concrete was measured with a standard slump cone (NP EN 12350-2, 2002) immediately after mixing and a slump of $30 \mathrm{~mm}$ was obtained.
Table 1

Chemical composition of metakaolin.

\begin{tabular}{llllllll}
\hline $\mathrm{SiO}_{2}$ & $\mathrm{Al}_{2} \mathrm{O}_{3}$ & $\mathrm{Fe}_{2} \mathrm{O}_{3}$ & $\mathrm{~K}_{2} \mathrm{O}$ & $\mathrm{Na}_{2} \mathrm{O}$ & $\mathrm{MgO}$ & $\mathrm{TiO}_{2}$ & Other minor oxides \\
\hline 50.75 & 43.48 & 2.45 & - & 0.04 & 0.11 & 0.57 & 2.6 \\
\hline
\end{tabular}

Table 2

Mix proportions and main properties of the OPC concrete substrate.

\begin{tabular}{ll}
\hline Components & Mix \\
\hline Cement II $32.5\left(\mathrm{~kg} / \mathrm{m}^{3}\right)$ & 400 \\
Fine river sand & 578 \\
Coarse aggregate & 1066 \\
$\mathrm{~W} / \mathrm{C}$ ratio & 0.53 \\
$\mathrm{fc}_{28 \mathrm{~d}}{ }^{\mathrm{a}}(\mathrm{MPa})$ & 20.3
\end{tabular}

a Average value of three specimens $(150 \times$ $\left.150 \times 150 \mathrm{~mm}^{3}\right)$.

Table 3

Properties of commercial pre-pack mortars.

\begin{tabular}{lllll}
\hline & $\mathrm{fc}_{28 \mathrm{~d}}(\mathrm{MPa})$ & $\mathrm{ft}_{28 \mathrm{~d}}(\mathrm{MPa})$ & Pull-off $_{14 \mathrm{~d}}(\mathrm{MPa})$ & Pull-off $_{28 \mathrm{~d}}(\mathrm{MPa})$ \\
\hline $\mathrm{R} 1$ & 45 & 9 & 2 & 2 \\
$\mathrm{R} 2$ & 49 & 8 & 1.5 & 1.8 \\
\hline
\end{tabular}



Fig. 3. CFRP strips.

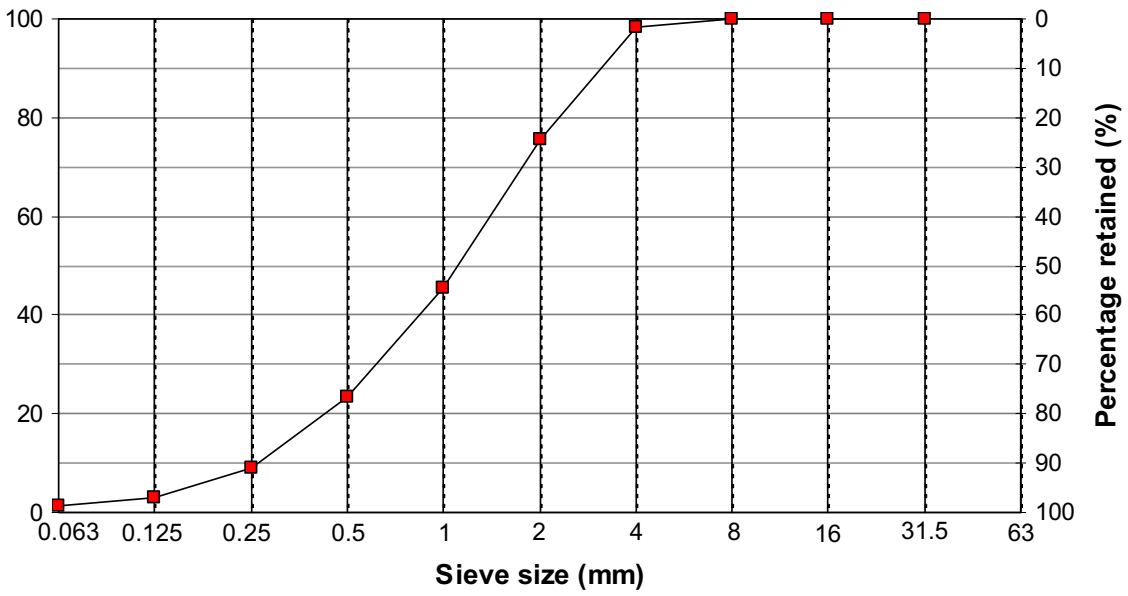

Fig. 2. Aggregate gradation. 
2.1.3. Commercial repair mortars

Two commercially available repair materials which are labelled R1 and R2 were also used in this study. The repair materials are supplied as pre-packed blend of graded aggregates with a maximum size $2 \mathrm{~mm}$, cement, silica fume, fibres and other additives. A water/powder ratio of 0.16 is recommended for use in material R1 and 0.14 for R2. The typical density of the fresh material is $2100 \mathrm{~kg} / \mathrm{m}^{3}$. The repair products are ready for on-site mixing and use, requiring only the addition of clean water. Table 3 presents the properties of the two commercial repair mortars as well as their adhesion strength obtained in the pull-off test for 14 and 28 curing days.

\subsubsection{CFRP sheets and epoxy adhesive}

CFRP sheets were provided in rolls (Fig. 3) by BASF and were composed by unidirectional carbon fibres with a commercial reference MBrace CF130 and their properties are shown in Table 4 . The medium viscosity epoxy adhesive used to bond the CFRP strips to concrete is a two components system (resin and hardener) with a commercial reference MapWrap 31 (Table 5). After mixing the two components the mixtures remains workable during $40 \mathrm{~min}$ at $23^{\circ} \mathrm{C}$.

\section{OPC concrete specimen preparation}

Figs. 4 and 5 show the preparation of OPC concrete slabs and concrete beams. The process starts with surface roughening
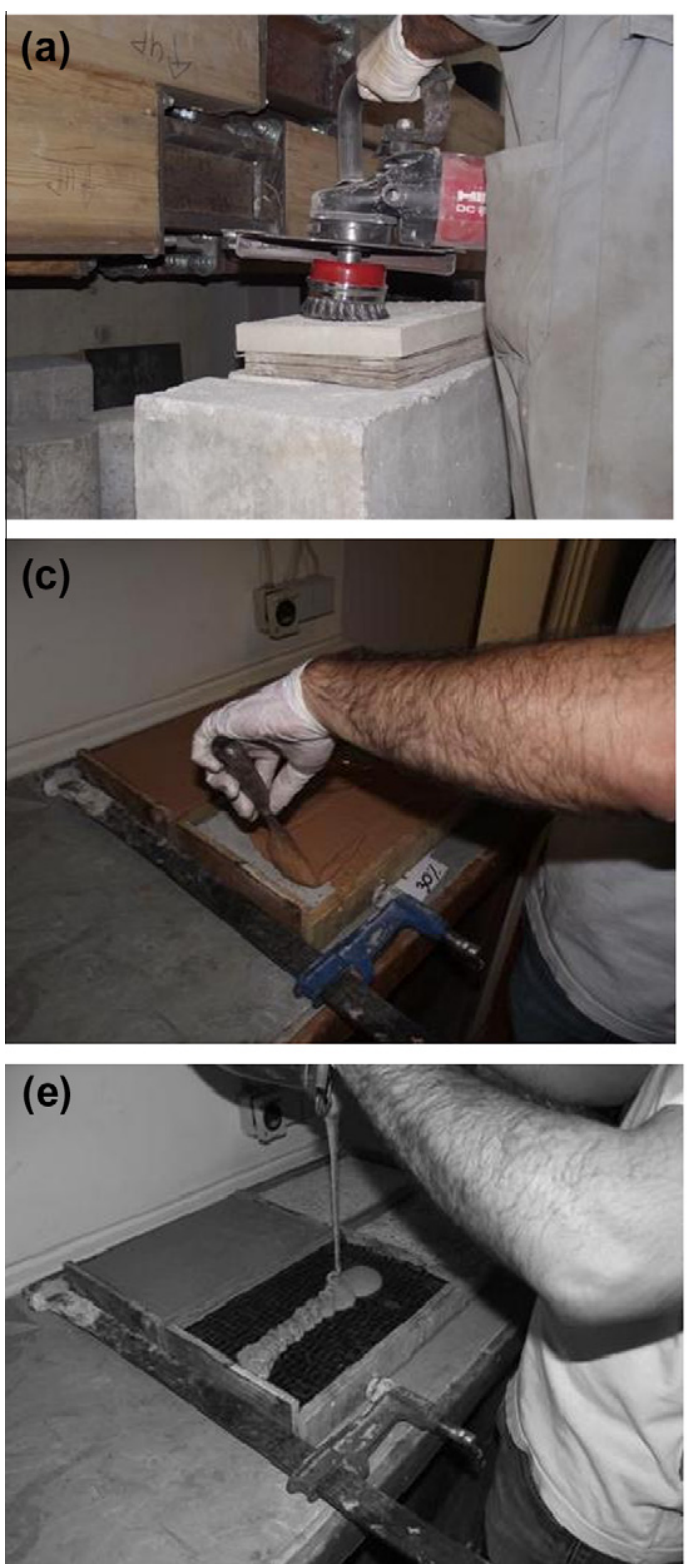

Table 4

Properties of CFRP sheets.

\begin{tabular}{ll}
\hline Properties & CF130 \\
\hline Thickness $(\mathrm{mm})$ & 0.176 \\
Width $(\mathrm{mm})$ & 300 \\
Length $(\mathrm{m})$ & 50 \\
Specific surface $\left(\mathrm{g} / \mathrm{cm}^{2}\right)$ & 300 \\
Tensile strength $(\mathrm{MPa})$ & 4900 \\
Young modulus $(\mathrm{GPa})$ & 230 \\
Elongation at break $(\%)$ & 2.1
\end{tabular}

Table 5

Properties of epoxy adhesive.

\begin{tabular}{ll}
\hline Properties & MapeWrape 31 \\
\hline Tensile strength (MPa) & $30 \mathrm{MPa}$ \\
Flexural strength (MPa) & $70 \mathrm{MPa}$ \\
Compressive strength (MPa) & $80 \mathrm{MPa}$ \\
Young modulus in flexion (GPa) & 3.8 \\
Young modulus in compression (GPa) & 3.0 \\
\hline
\end{tabular}
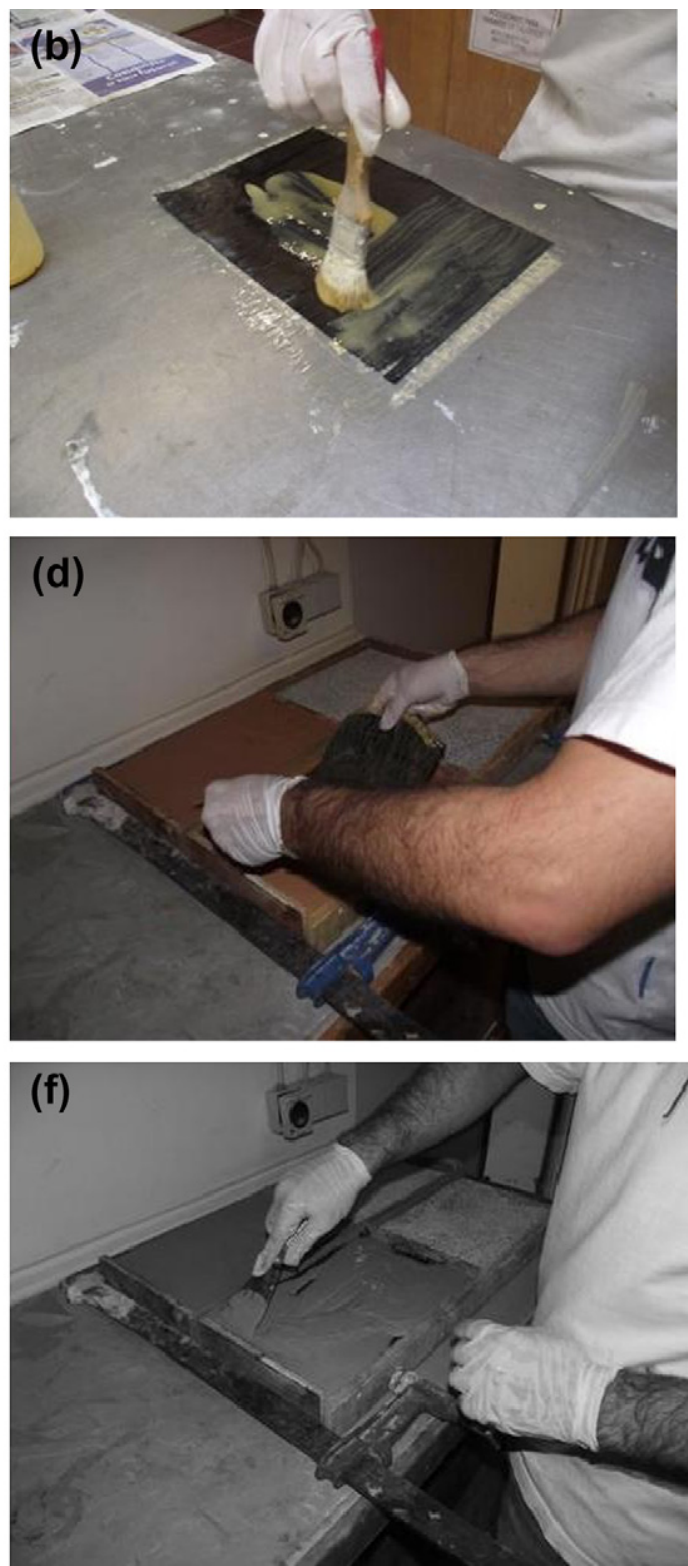

Fig. 4. OPC concrete slabs preparation: (a) surface roughening; (b) CFRP sheets impregnation; (c) applying the geopolymeric mortar; (d) placing the CFRP sheet; (e and f) applying a second layer of geopolymeric mortar. 

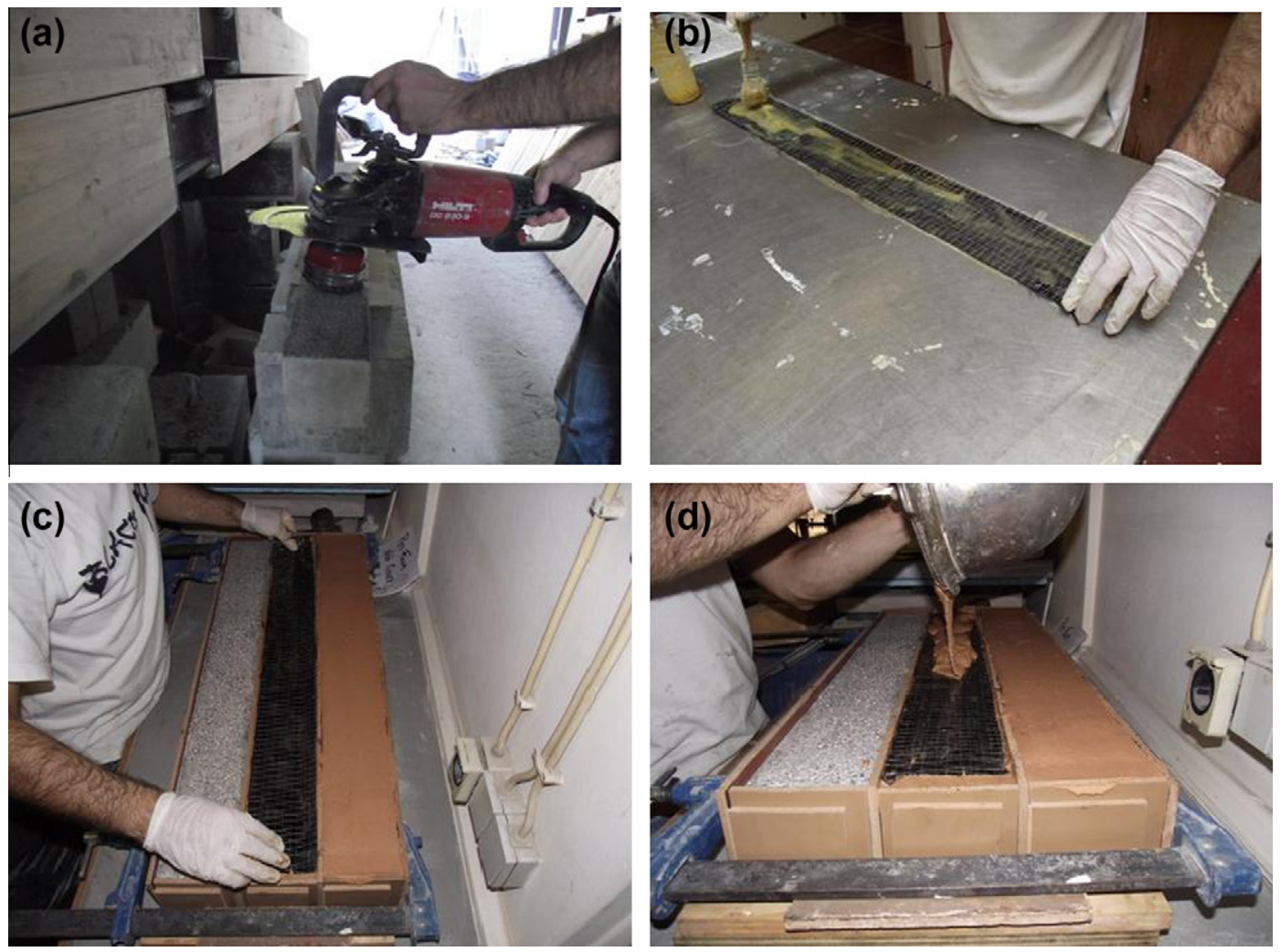

Fig. 5. OPC concrete beams preparation: (a) surface roughening; (b) CFRP sheets impregnation; (c) Placing the CFRP sheet over the geopolymeric mortar; (d) applying a second layer of geopolymeric mortar.

Table 6

OPC concrete beams characteristics.

\begin{tabular}{llll}
\hline Ref. & Description & Geopolymeric mortar composition \\
\cline { 3 - 4 } & & $\begin{array}{l}\text { Sodium hydroxide } \\
\text { concentration }\end{array}$ & $\begin{array}{l}\text { Calcium hydroxide } \\
\text { content (\%) }\end{array}$ \\
\hline CFRP0 & Plain concrete & - & - \\
CFRP1 & Concrete reinforced with CFRP and epoxy adhesive & - & - \\
CFRP2 & Concrete reinforced with CFRP and geopolymeric mortar & $14 \mathrm{M})$ & - \\
CFRP3 & & & - \\
CFRP5 & & & 30 \\
\hline
\end{tabular}

operations to remove grease, oils, free particles, laintance and also producing a irregular surface. Then a geopolymeric mortar are applied followed by the CFRP sheets with $800 \mathrm{~mm}$ and a second layer of geopolymeric mortar.

\section{Test procedures}

\subsection{Compressive and flexural strength testing}

Compressive and flexural strength data of geopolimeric mortars was obtained using $160 \times 40 \times 40 \mathrm{~mm}^{3}$ cubic specimens according to EN 1015-11. The fresh mortar were cast and allowed to set at room temperature for $24 \mathrm{~h}$ before being removed from the moulds and kept at room temperature $\left(20^{\circ} \mathrm{C}\right)$ until tested in compression and flexural strength. Compressive strength for each mortar mixture was obtained from an average of at least 3 specimens. Flexural strength of concrete specimens uses $850 \times 100 \times 80 \mathrm{~mm}$ beams reinforced by CFRP sheets and is done according to NP EN 12390-5. The flexural tests were conducted with an electrohydraulic universal testing machine, at a controlled rate of axial displacement. The supports were placed $25 \mathrm{~mm}$ from the begin- ning of the beams. Table 6 shows the characteristics of the concrete beams tested.

\subsection{Pull-off}

The adhesion strength was assess by pull-off test according to EN 1015-12. This test uses a Proceq Dyna Z15 device and a epoxi adhesive with a commercial reference Icosit K101.The adhesion strength was obtained from an average of six pull-off test specimens.

\section{Results and discussion}

\subsection{Compressive and flexural strength testing of geopolymeric mortars}

Fig. 6 presents the results of the compressive strength according to the curing days for geopolymeric mortar mixtures with several sodium hydroxide concentrations and several sand/binder mass ratios. The coefficient of variation was lower than $15 \%$. After 7 days curing all the mixtures present a compressive strength above $30 \mathrm{MPa}$. The results show that higher sodium hydroxide concentra- 
Sand $/$ binder mass ratio $=30 \%$

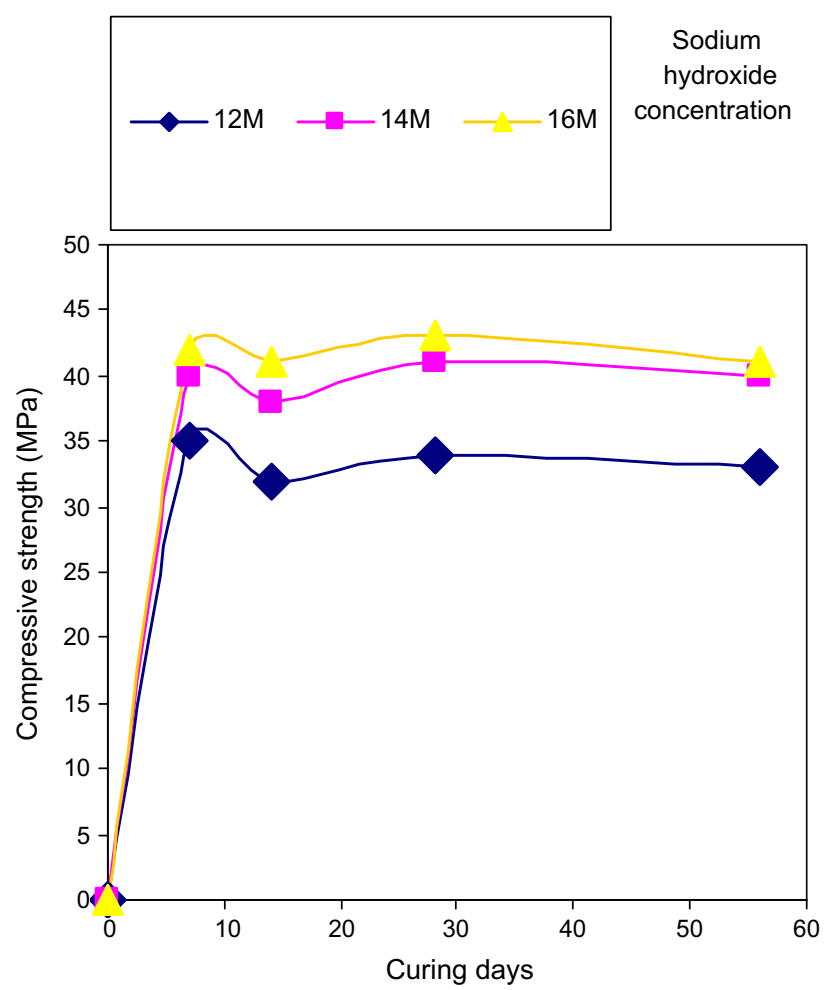

Sand $/$ binder mass ratio $=60 \%$

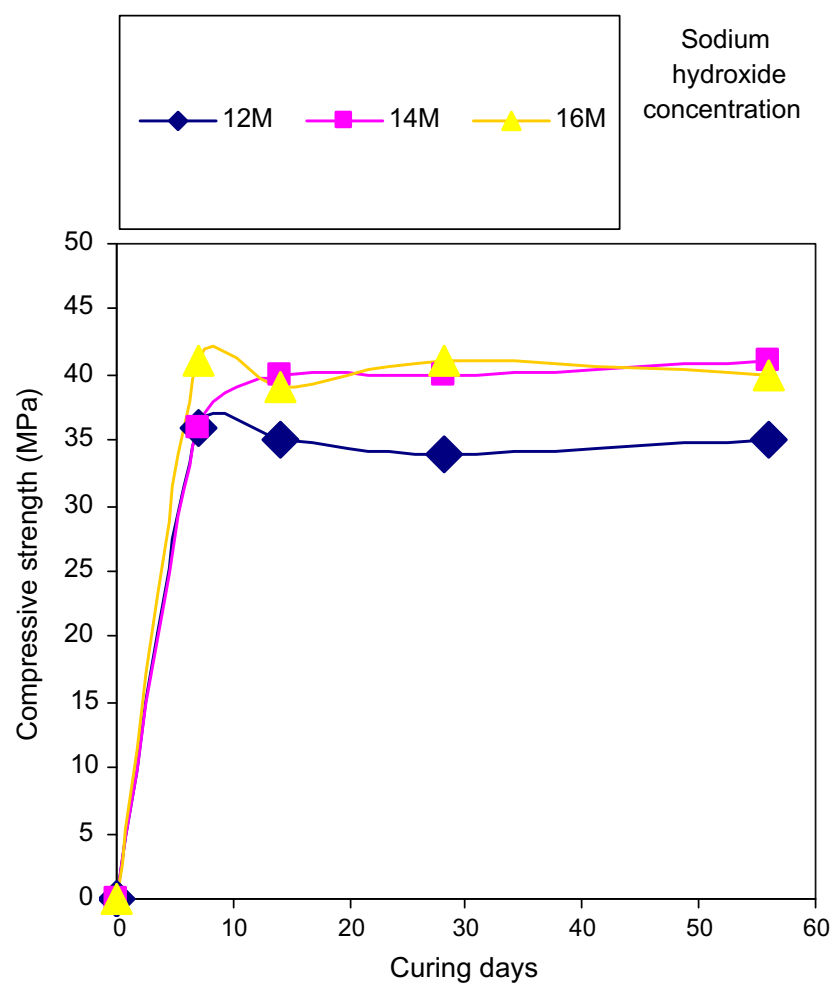

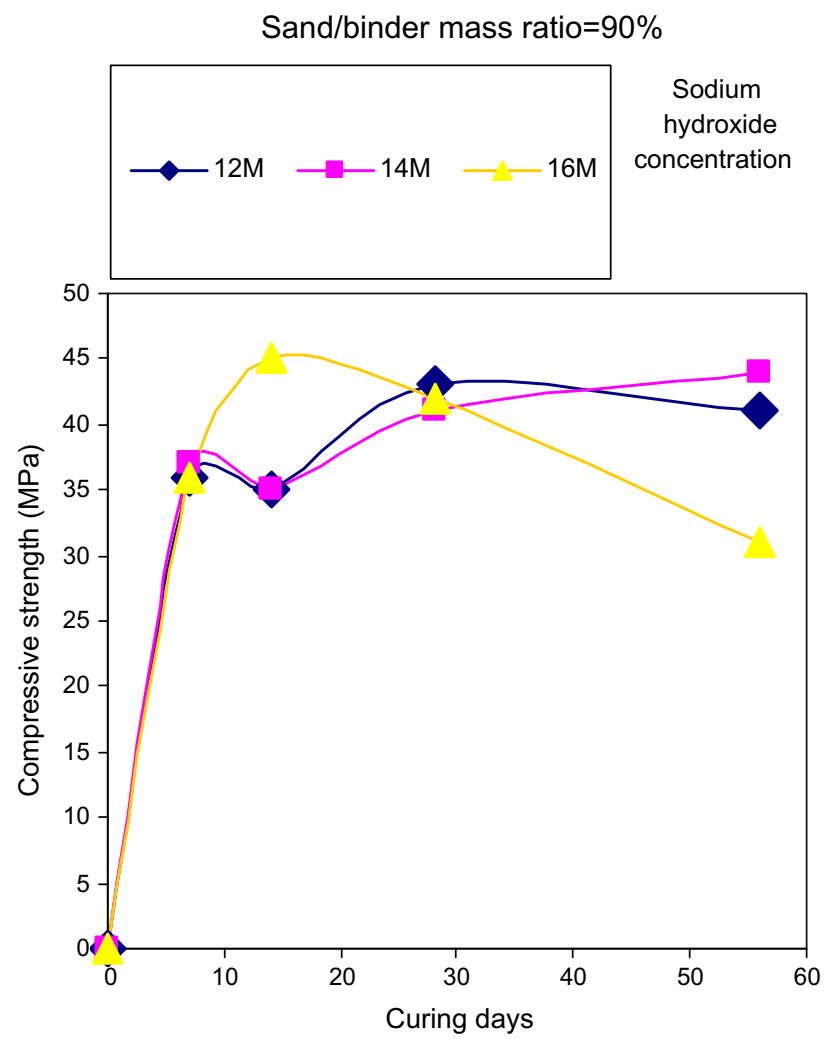

Fig. 6. Compressive strength according to curing days for geopolymeric mortar mixtures with several sodium hydroxide concentrations (12 M, $14 \mathrm{M}, 16 \mathrm{M}$ ) and several sand/ binder mass ratios (30\%; 60\%, $90 \%$ ).

tions lead to a compressive strength increase, but that only happens beyond 7 days curing. Higher concentrations of alkaline solution raises the $\mathrm{pH}$ which increases the dissolution and solubility of the aluminosilicate mineral waste and provides positive ions to balance the negative charge of the aluminate group [13,14]. The adverse effect reported by Lee et al. [15] related to reduction in strength due to excess of alkali have not been confirm with the exception of the mixture containing a sodium hydroxide concen- 



Fig. 7. Compressive strength versus $\mathrm{H}_{2} \mathrm{O} / \mathrm{Na}_{2} \mathrm{O}$ atomic ratio according to curing days for geopolymeric mortars with several sand/binder mass ratio (30\%; $60 \%$, $90 \%$ ).

tration of $16 \mathrm{M}$ and a sand/binder mass ratio of $90 \%$. Fig. 7 shows the compressive strength versus $\mathrm{H}_{2} \mathrm{O} / \mathrm{Na}_{2} \mathrm{O}$ atomic ratio according to curing days for geopolymeric mortars with several sand/binder mass ratios. Although other authors [6] obtained a lower compressive strength for the same sodium hydroxide concentration and calcium hydroxide content (30 MPa for $16 \mathrm{M}$ and $10 \%$ lime), when using tungsten mine waste mud the explanation for that is not entirely related to the different reactivity between the metakaolin and the tungsten mine waste mud. The different results are much more related to the $\mathrm{H}_{2} \mathrm{O} / \mathrm{Na}_{2} \mathrm{O}$ parameter which is 8.9 ( $16 \mathrm{M}$ ) in the present study and was 13.4 for those authors. Flexural strength results are present in Fig. 8. The results represent $10-15 \%$ of the compressive strength. This is quite similar to the behaviour observed for ordinary Portland cement based concrete. Similar findings were reported by others using fly-ash based geopolymeric binders [16]. However, Pacheco-Torgal et al. [17] reported a ft/fc ratio around 

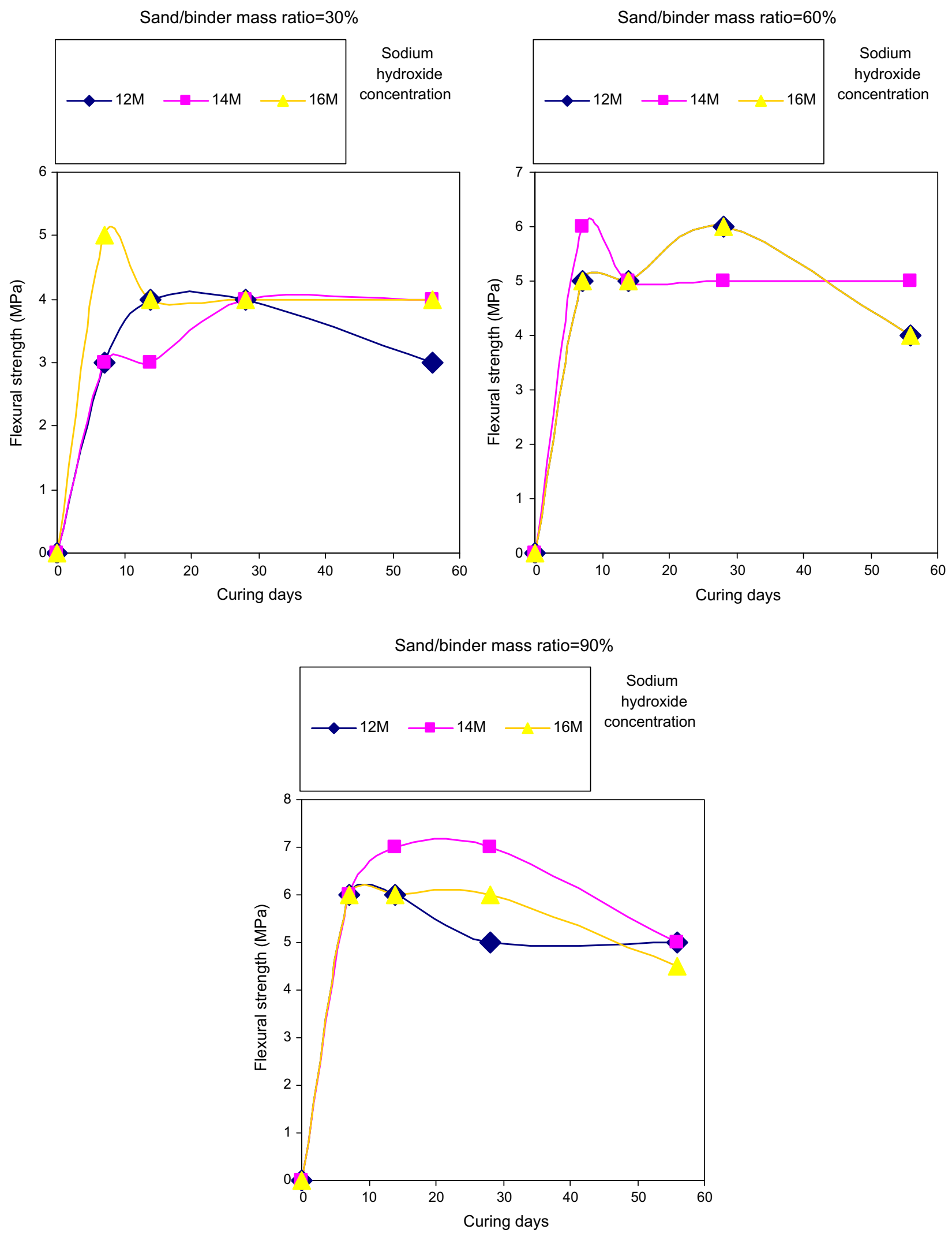

Fig. 8. Flexural strength according to curing days for geopolymeric mortar mixtures with several sodium hydroxide concentrations (12 M, $14 \mathrm{M}$, $16 \mathrm{M}$ ) and several sand/ binder mass ratio $(30 \% ; 60 \%, 90 \%)$.

20-25\% for tungsten mine waste based geopolymeric mortars. The flexural strength loss with curing time observed in several mixtures, is probably due to the fact that $\mathrm{CSH}$ reaction and the geopol- imeric reaction will compete against each other for soluble silicates, and give rise to a binder composed of two porous phases which leads to strength loss $[18,19]$. An alternative explanation is 

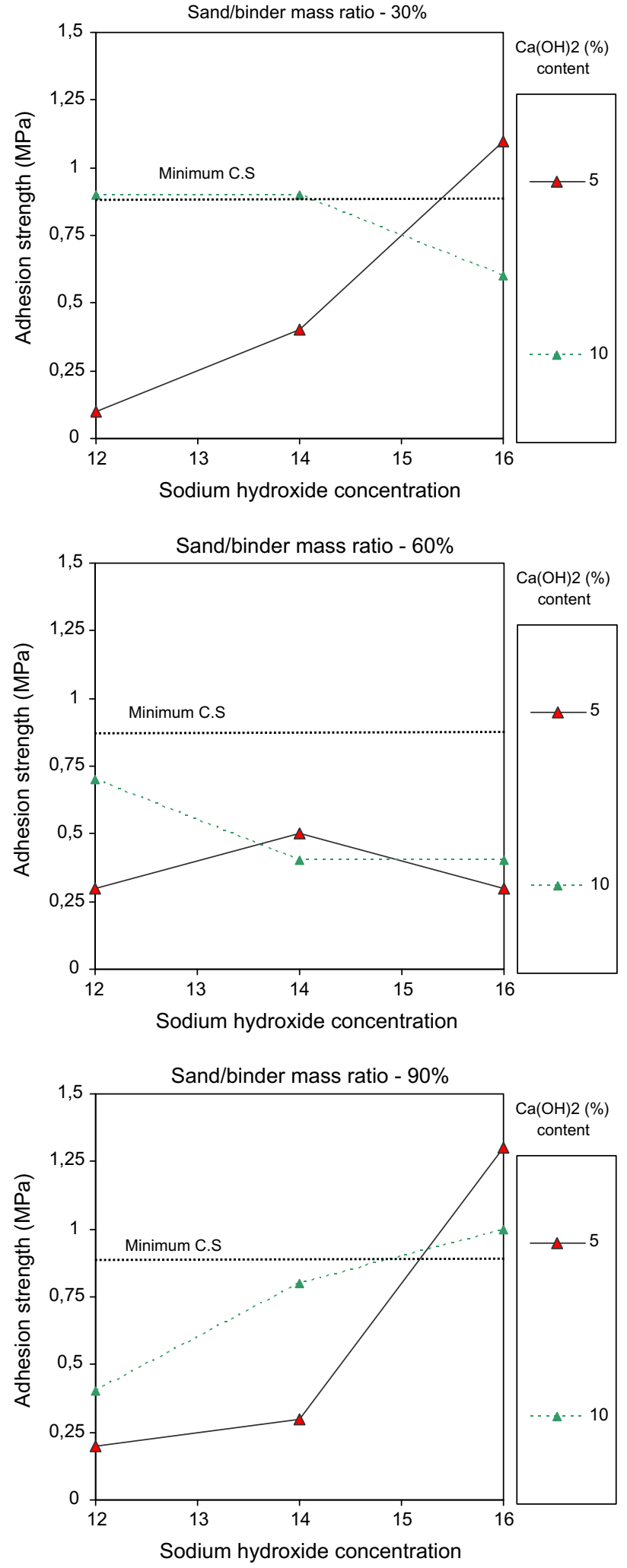

Fig. 9. Adhesion strength between OPC concrete specimens and geopolymeric mortar mixtures according to the sodium hydroxide concentration (12 M, $14 \mathrm{M}$ $16 \mathrm{M})$ and the sand/binder mass ratio (30\%; 60\%, 90\%).

related to the possibility of the occurrence of shrinkage cracking near the aggregates, originating a clear tensile strength reduction [20], that could only be confirmed when shrinkage and tensile strength were studied. And a third explanation is related to the for-



(b)

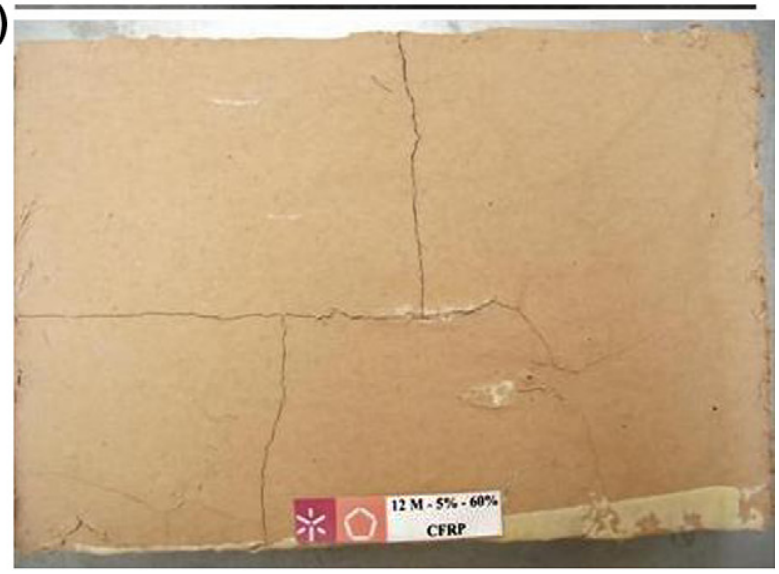

(c)

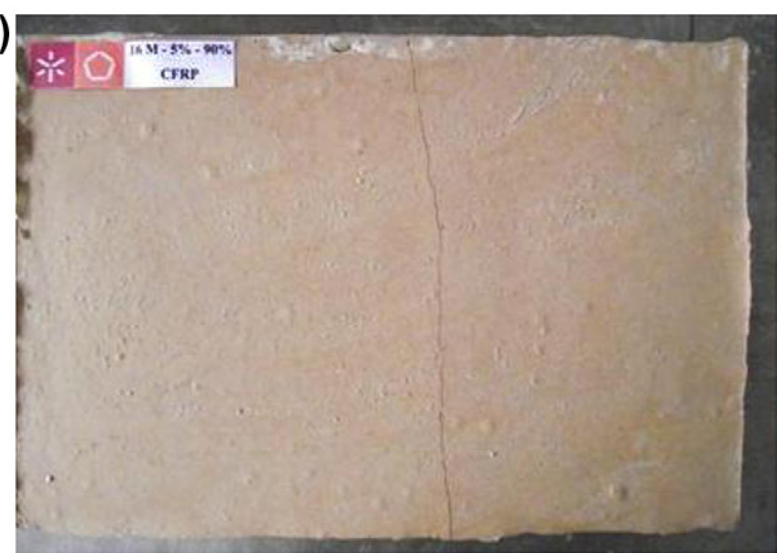

Fig. 10. Influence of sand/binder mass ratio on the shrinkage performance: (a) $30 \%$; (b) $60 \%$; (c) $90 \%$.

mation of gel similar to the one that takes place in ASR of Portland cement binders, so that the gel volume increase would explain strength loss.

\subsection{Adhesion strength}

\subsubsection{Geopolymeric mortars as a repairing layer}

The adhesion strength between OPC concrete specimens and geopolymeric mortar mixtures according to the sodium hydroxide concentration and the sand/binder mass ratio is shown in Fig. 9. The mixtures with a sand/binder mass ratio of $60 \%$ have adhesion strength lower than the minimum recommended by the Concrete Society (0.8 MPa). The adhesion strength is lower than the one obtained with geopolymeric mortars. This finding is opposite to the 


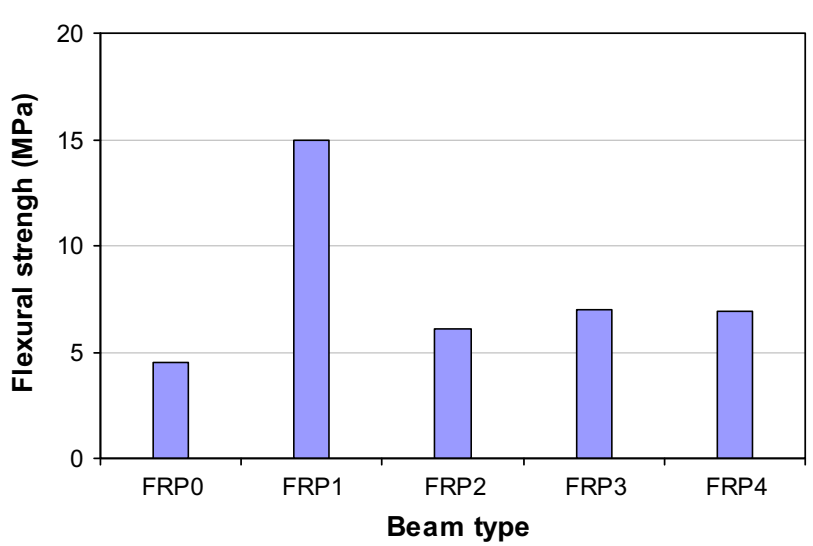

Fig. 11. Flexural strength of $O P C$ concrete beams reinforced with geopolymeric mortars and CFRP.

adhesion strength observed by other authors [8]. The explanation could be due to the fact that the mortars with lower sand/binder mass ratio present a high shrinkage behaviour that was observed in this work because the surface of the specimens with a lower sand content presented a high level of microcracks (Fig. 10). Nevertheless, since metakaolin based geopolymeric mortars are much cost-effective (5-10 times less expensive) this means that they represent a serious alternative to commercial mortars.

\subsubsection{Geopolymeric mortars used as adhesive for CFRP}

The pull-off strength results were all below $0.2 \mathrm{MPa}$. The explanation is probably related to the shrinkage behaviour of the metakaolin mortars (Fig. 10). Another explanation maybe due to the fact that the geopolymeric mortar mixture was not optimized. Also this CFRP sheets probably are not the best option for this purpose. Further investigations in order to find the best CFRP sheets to be used with geopolymeric binders are needed. As for the flexural strength of concrete beams reinforced with CFRP sheets (Fig. 11), the results confirm that using a epoxy adhesive (FRP1) is a better option to insure the adhesion between concrete and FRP compared to use of geopolymeric mortars.

\section{Conclusions}

One of the largest disadvantages of geopolymeric binders is that they are more expensive than Portland cement based ones. The explanation for their high cost lies essentially in the cost of the chemical activators. This context show us that for the time being investigations should focus on high cost applications such as concrete repair materials. Based on the experimental results the following conclusions can be drawn. Metakaolin geopolimeric mortars with low sand/binder mass ratio present low adhesion to concrete substrate due to high shrinkage behaviour deduced by the microcracks in the surface of the specimens. Although the mortars tested show adhesion strength lower than the commercial repair mortars the former are much more cost-effective (5-10 times less expensive). Further investigations in order to find optimized mortar compositions and the appropriate CFRP sheets to insure maximum adhesion are still needed.

\section{References}

[1] Duxson P, Provis J, Lukey G, Van Deventer J. The role of inorganic polymer technology in the development of green concrete. Cem Concr Res 2007;37:1590-7.

[2] Weil M, Dombrowski K, Buchawald A. Life-cycle analysis of geopolymers. In: Provis J, Van Deventer J, editors. Geopolymers, structure, processing, properties and applications. Cambridge, UK: Woodhead Publishing Limited Abington Hall; 2009. p. 194-210. ISBN-13: 9781845694494

[3] Davidovits J. Chemistry of geopolymeric systems, terminology. In: Proceedings of 99 geopolymere conference, vol. 1; 1999. p. 9-40.

[4] Deventer SJ. Opportunities ans obstacles in the commercialisation of geopolymers. Geopolymer; 2002 [Melbourne].

[5] Harper R, South W, Knigth R. Geopolymers - a commercial reality? In: Proceedings of 2002 geopolymer conference. Melbourne, Australia.

[6] Pacheco-Torgal F, Gomes JP, Jalali Said. Investigations on mix design of tungsten mine waste geopolymeric binders. Construct Build Mater 2008;22:1939-49.

[7] Pacheco-Torgal F, Gomes JP, Jalali Said. Tungsten mine waste geopolymeric binders. Preliminary hydration products. Construct Build Mater - Elsevier 2009;23:200-9.

[8] Pacheco-Torgal F, Gomes JP, Jalali Said. Adhesion characterization of tungsten mine waste geopolymeric binder. Influence of OPC concrete substrate treatment. Construct Build Mater 2008;22:154-61.

[9] Fukuyama H, Sugano S. Japanese seismic rehabilitation of concrete building after the Hyogoken Nanbu Earthquake. Cem Concr Compos 2000;22(1):59-79.

[10] Badanoiu A, Holmgren J. Cementitious composites reinforced with continuous carbon fibres for strengthening of concrete structures. Cem Concr Compos 2003;25:387-94.

[11] Gamage JCPH, Al-Mahaidi R, Wong MB. Bond characteristics of CFRP plated concrete members under elevated temperatures. Compos Struct 2006;75:199-205.

[12] Yip CK, Lukey GC, Deventer SJS. The coexistence of geopolymeric gel and calcium silicate hydrate gel at the early stage of alkaline activation. Cem Concr Res 2005;35:1688-97.

[13] Rattanasak U, Chindaprasirt P. Influence of $\mathrm{NaOH}$ solution on the synthesis of fly ash geopolymer. Miner Eng 2009;22(12):1073-8.

[14] Chindaprasirt P, Jaturapitakkul C, Chalee W, Rattanasak U. Comparative study on the characteristics of fly ash and bottom ash geopolymers. Waste Manage 2009;29:539-43.

[15] Lee WKW, Van Deventer JSJ. The effects of inorganic salt contamination on the strength and durability of geopolymers. Colloids Surf 2002;211:115-26.

[16] Rangan B. Engineering properties of geopolymer concrete. In: Provis J, Van Deventer J, editors. Geopolymers, structure, processing, properties and applications. Cambridge, UK: Woodhead Publishing Limited Abington Hall; p. 211-26, 2009. ISBN-13: 9781845694494.

[17] Pacheco-Torgal F, Gomes JP, Jalali S. Investigations about the effect of aggregates on strength and microstructure of geopolymeric mine waste mud binders. Cem Concr Res 2007;37:933-41.

[18] Xiaolu G, Huisheng S, Warren AD. Compressive strength and microstructural characteristics of class C. Fly ash geopolymer. Cem Concr Compos 2010;2:142-7.

[19] De Silva P, Sagoe-Crenstil K, Sirivivatnanon V. Kinetics of geopolymerization: role of $\mathrm{Al}_{2} \mathrm{O}_{3}$ and $\mathrm{SiO}_{2}$. Cem Concr Res 2007;37:512-8.

[20] Wongpa J, Kiattikomol K, Jaturapitakkul C, Chindaprasirt P. Compressive strength, modulus of elasticity, and water permeability of inorganic polymer concrete. Mater Des 2010;31:4748-54. 